Revue française de la traduction

\title{
Aspects culturels de la traduction technique
}

\section{Natacha Dalügge-Momme}

\section{OpenEdition}

Journals

Édition électronique

URL : http://journals.openedition.org/traduire/959

DOI : 10.4000/traduire.959

ISSN : 2272-9992

\section{Éditeur}

Société française des traducteurs

\section{Édition imprimée}

Date de publication : 1 juin 2008

Pagination : 5-13

ISSN : 0395-773X

\section{Référence électronique}

Natacha Dalügge-Momme, « Aspects culturels de la traduction technique », Traduire [En ligne],

217 | 2008, mis en ligne le 01 juin 2008, consulté le 19 avril 2019. URL : http://

journals.openedition.org/traduire/959 ; DOI : 10.4000/traduire.959 


\title{
Aspects culturels de la traduction technique
}

\author{
NaTACHA DALÜGge-MoMme
}

"La traduction est le fait d'interpréter le sens d'un texte dans une langue (langue source, ou langue de départ), et de produire un texte ayant un sens et un effet équivalents sur un lecteur ayant une langue et une culture différentes (langue cible, ou langue d'arrivée)(1) ».

Comme la plupart des gens, certains traducteurs et interprètes n'associent pas tout naturellement le terme de « culture " à celui de « traduction ", une association qui évoquerait plutôt la " traduction littéraire ». Aujourd'hui encore, plusieurs théoriciens de la traduction affirment sans relâche que les termes techniques peuvent être reproduits terme à terme dans la langue cible, ne laissant plus au traducteur que le soin de retrouver le terme équivalent. La traduction technique, comparée à la traduction juridique, serait donc la plus simple des disciplines. De même, il est fréquent de considérer la traduction de textes juridiques comme une transposition culturelle due aux différents systèmes juridiques. Or, comment ne pas reconnaître que le traducteur et l'interprète sont les médiateurs d'une culture et, partant d'une culture de production, de consommation et de métier, quel qu'il soit. Il en découle inévitablement que différentes difficultés dans l'acte de traduire, tant au niveau de la traduction elle-même que de la transposition culturelle d'un texte, apparaîtront au traducteur d'un texte vers une langue africaine comme le soussou, le lingala, alors qu’il ne sera pas nécessairement conscient des difficultés qui l'attendent en traduisant un texte allemand vers le français ou inversement. Pour étayer mon propos, je

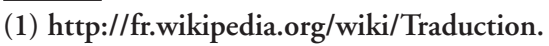


tirerai des exemples de mes propres traductions et en emprunterai d'autres aux professeurs Schmitt (Université de Leipzig) et Schmitz (Université de Cologne), en les adaptant au français.

L'interprétation est toujours influencée par la culture, et la régionalisation du texte est un élément essentiel de la traduction, aussi y a-t-il lieu d'être lucide face aux difficultés. Le traducteur tentera, dans un premier temps, de définir le terme "culture ». Que signifie culture dans le texte en présence ? S'agit-il de culture régionale, allemande ou française, de culture d'entreprise (Unternehmenskultur) et donc de socioculture ? Les entreprises Siemens et Tefal ont des cultures d'entreprises indubitablement très différentes, comme Aerospace et EADS en ont une autre, sans aller jusqu'à faire cas de l'idioculture, culture propre à chaque individu, ce qui nous entraînerait trop loin.

Le traducteur en tiendra néanmoins compte dans l'analyse du texte qu'il traduit, restant conscient qu'un même vocable peut faire référence à deux réalités différentes : " portable " peut évoquer aussi bien le téléphone que l'ordinateur. Il importe donc de savoir ce que l'auteur a voulu impliquer par le terme employé. Prenons le substantif « couteau ». Un Allemand pensera probablement au couteau de scout (Fahrtenmesser), un Suisse au couteau de l'armée suisse (Schweizermesser), un Français au couteau Laguiole ou à un Opinel. Il en est de même pour les marteaux : un Allemand pensera à un marteau de mécanicien, un Américain à un marteau à panne fendue et un Français probablement à un marteau de menuisier. Et, selon le texte, la traduction de ce terme jouera un rôle ou non, car seul le marteau américain sera en mesure de retirer des clous !

Le recours aux dictionnaires permet de remédier à ces problèmes. Le traducteur pourra y trouver des explications socioculturelles précisant le contexte dans lequel les termes sont employés. Les possibilités sont néanmoins restreintes. Et il faut de la place pour se livrer à des études contrastives. L'idéal serait donc d'avoir accès à des explications, voire des illustrations dans des dictionnaires commentés et illustrés, plutôt rares. Il incombe donc aux traducteurs eux-mêmes de créer des répertoires et de les tenir à jour. 
Prenons un autre terme : "Lastkraftwagen" en allemand peut tout aussi bien signifier " véhicule utilitaire " que " camion ", tout simplement. En anglais " truck» ou "lorry " nous donneront une tout autre image. De même faudra-t-il faire la différence entre les camions à cabine avancée (Frontlenker), plus répandus en Europe pour des raisons de norme de longueur des routes, et les camions à capot (Haubenfahrzeuge). Le choix à opérer dépendra donc du texte ou du client.

Citons à présent un autre exemple issu du domaine alimentaire : la glace (une Speiseeis) en Allemagne doit contenir $70 \%$ de lait entier, donnant une teneur en graisse minimale de 2,4\%. Elle contient également du sucre et des arômes. En France, le terme générique "glace " regroupera tout aussi bien les crèmes glacées que les sorbets. La crème glacée contiendra de la crème, des œufs, du lait écrémé et du sucre. Une Speiseeis contenant au moins $22 \%$ de matière grasse serait donc... un sorbet au lait ? Ces différences sont dues aux lois alimentaires non homologuées. Les produits laitiers constituent un problème particulier en traduction, chaque pays disposant de ses propres spécialités (Frischrahm - crème fraîche ; Saure Sahne - crème aigre, dite sure au Canada ; Schlagsahne - crème chantilly - whipped cream).

Une hiérarchie non congruente de termes constitue une autre source d'erreurs de traduction. Le domaine des métaux en est un exemple parlant. Il est d'usage, dans les dictionnaires, de traduire les termes " acier au carbone " par "Koblenstoffstahl» ou "Koblenstahl», ce qui n'est que partiellement exact voire inexact. Il faudrait y préciser que le "Kohlenstoffstahl» peut aussi bien désigner le "Baustahl» (acier de construction), le "Werkzengstahl» (acier à outil), voire l' "Edelstahl» (acier inoxydable avec une teneur en carbone très réduite). Dans ces cas, se référer aux normes ne sera d'aucune utilité, car il n'existe pas de correspondance terminologique totale entre tous les pays et langues respectives, étant donné les différences de tradition de la fonderie d'acier. Plutôt que de se fier aux normes, il est indispensable pour la bonne traduction de respecter la catégorisation du terme et de recourir aux spécialistes. 
Certaines lacunes lexicales peuvent également prêter à confusion. Le terme «schweißen " en allemand est généralement traduit par "souder ", mais il peut aussi signifier "entrer en fusion ". Il conviendra donc, si possible, de préciser qu'il s'agit de "Schmelzschweißen " (soudage par fusion) et de l'opposer à "Preßschweißen " (soudage par pression) qui représente une sous-catégorie du processus de soudage, tandis qu'en français, les procédés de soudage sont exprimés par des substantifs explicatifs.

Dans la liste des sources de malentendus, figurent aussi les termes en rapport avec les normes et les mesures. Ainsi, le terme "Entflammbarkeit " est traduit par "inflammabilité ", ce qui semble de prime abord être une traduction adéquate. Considérons la définition allemande : "Entflammbarkeit ist ein Maß dafiur, wie leicht sich ein Stoff bei natürlichen Temperaturen entzündet " (il est ici question, en allemand, de température naturelle), puis la définition française : «L'inflammabilité est la capacité d'un matériau à s'enflammer plus ou moins facilement au contact d'une flamme, d'une étincelle ou bien d'une température élevée ». Les normes sont donc différentes selon les matériaux ; un recensement serait long, fastidieux et aurait peu de sens, on se référera donc ici à la norme la plus importante, la norme ISO 13943 ("Sécurité au feu » et "Brandschutz»).

Pour qualifier la mesure de filtre à tamis, on utilise, dans le domaine de l'ingénierie, le terme de "Maschenweite", par exemple. Il définit l'ouverture de la maille et non la mesure " mesh » souvent utilisée en France pour indiquer le nombre d'ouvertures par pouce, autrement dit par unité de longueur.

La diffusion propre à la culture du pays influence également la langue. Ainsi, en Allemagne, de plus en plus de détecteurs d'incendie (Brandmelder) sont installés dans les maisons individuelles, alors qu'en France une loi a été adoptée dès 2005 (13/10/2005) par l'Assemblée nationale. Cette loi oblige chaque propriétaire ou occupant d'une habitation à installer et à entretenir, au minimum, un Détecteur avertisseur autonome de fumée (D.A.A.F.) certifié. La France était l'un 
des derniers pays européens à ne pas avoir légiféré sur la sécurité incendie domestique et ce, malgré une forte augmentation du nombre de victimes. En Allemagne, seules $10 \%$ des habitations sont munies de ce système. Il n'existe pas de loi au niveau national. Les Länder ont chacun leur réglementation de la construction (Bauverordnung), comme en témoigne le tableau ci-dessous :

\begin{tabular}{|c|c|c|c|}
\hline Land & $\begin{array}{c}\text { Ordonnances } \\
\text { sur la construction }\end{array}$ & $\begin{array}{l}\text { Date de } \\
\text { l'adoption }\end{array}$ & Remarque \\
\hline $\begin{array}{l}\text { Rhénanie- } \\
\text { Palatinat }\end{array}$ & $\begin{array}{c}\text { Ordonnance } \\
\text { du Land } \\
\text { de Rhénanie-Palatinat } \\
\$ 44 \text { alinéa } 8\end{array}$ & 22 déc. 2003 & $\begin{array}{l}\text { S'applique aux construc- } \\
\text { tions nouvelles et aux trans- } \\
\text { formations de logements. } \\
\text { En outre, depuis le } 27 \text { juin } \\
2007 \text {, l'équipement d'habi- } \\
\text { tations existantes doit être } \\
\text { complété par un détecteur } \\
\text { de fumée (délai : } 5 \text { ans). }\end{array}$ \\
\hline Sarre & $\begin{array}{l}\text { Ordonnance } \\
\text { du Land } \\
\text { de Sarre } \\
\$ 46 \text { alinéa } 4\end{array}$ & 18 fév. 2004 & $\begin{array}{l}\text { S'applique aux construc- } \\
\text { tions neuves et aux trans- } \\
\text { formations de logements. }\end{array}$ \\
\hline $\begin{array}{l}\text { Schleswig- } \\
\text { Holstein }\end{array}$ & $\begin{array}{c}\text { Ordonnance du Land } \\
\text { de Schleswig-Holstein } \\
\$ 52 \text { alinéa } 7\end{array}$ & 01 jan. 2005 & $\begin{array}{l}\text { S'applique aux construc- } \\
\text { tions neuves et aux trans- } \\
\text { formations de logements. } \\
\text { En outre, tous les apparte- } \\
\text { ments existants du Land } \\
\text { doivent être équipés de } \\
\text { détecteurs de fumée d'ici } \\
\text { fin } 2009 \text {. }\end{array}$ \\
\hline Hesse & $\begin{array}{c}\text { Ordonnance du Land } \\
\text { de Hesse } \\
\$ 13 \text { alinéa } 5\end{array}$ & 24 juin 2005 & $\begin{array}{l}\text { S'applique aux construc- } \\
\text { tions neuves à usage } \\
\text { d'habitation. En outre, tous } \\
\text { les logements existants du } \\
\text { Land doivent être équipés } \\
\text { de détecteurs de fumée d'ici } \\
\text { fin } 2014 \text {. }\end{array}$ \\
\hline
\end{tabular}




\begin{tabular}{|c|c|c|c|}
\hline Hambourg & $\begin{array}{l}\text { Ordonnance } \\
\text { du Land } \\
\text { de Hambourg } \\
\$ 45 \text { alinéa } 6\end{array}$ & 7 déc. 2005 & $\begin{array}{l}\text { S'applique aux construc- } \\
\text { tions neuves et aux trans- } \\
\text { formations de logements. } \\
\text { En outre, tous les loge- } \\
\text { ments existants du Land } \\
\text { doivent être équipés de } \\
\text { détecteurs de fumée d'ici } \\
\text { fin } 2010 \text {. }\end{array}$ \\
\hline $\begin{array}{l}\text { Mecklembourg- } \\
\text { Poméranie } \\
\text { occidentale }\end{array}$ & $\begin{array}{c}\$ 48 \text { alinéa } 4 \\
\text { Ordonnance } \\
\text { du Land } \\
\text { de Mecklembourg- } \\
\text { Poméranie occidentale }\end{array}$ & 18 avr. 2006 & $\begin{array}{l}\text { S'applique aux construc- } \\
\text { tions neuves et aux trans- } \\
\text { formations de logements. } \\
\text { En outre, tous les loge- } \\
\text { ments existants du Land } \\
\text { doivent être équipés de } \\
\text { détecteurs de fumée d'ici } \\
\text { fin } 2009 \text {. }\end{array}$ \\
\hline
\end{tabular}

Extrait de l'Ordonnance fédérale sur la construction en RhénaniePalatinat (\$ 44 alinéa 8$)$ :

Dans les logements, les chambres à coucher et les chambres d'enfants, ainsi que les couloirs pouvant servir de voies d'évacuation à des pièces de séjour doivent être équipés d'au moins un détecteur de fumée chacun. Les détecteurs de fumée doivent être montés et exploités de façon à ce que la fumée provenant d'un incendie puisse être perçue et signalée à temps(2).

Dénomination de réalités inexistantes dans la langue du pays d'arrivée et noms de marque génériques

Pour illustration, reprenons l'exemple classique dans le domaine de la traduction technique, du mot "Autobahn" vers l'anglais américain ou le français canadien. Peut-on tout simplement traduire par "superhighway " (autoroute, route express), "freeway " (autoroute au Québec), "motorway " ou faut-il ajouter dans tous les cas l'adjectif

(2) Article « Bauverordnung » de wikipedia.de. 
"German" ? On rencontre ce problème assez souvent dans le domaine de la construction qui, en Allemagne, est régi par des normes et lois différentes de celles de la France ou du Canada.

Pour traduire le mot "Klinkers" (pavé), on conserve le plus souvent le terme "klinkers ", avec minuscule et explication éventuelle. Il en est de même pour les noms génériques français comme " fibragglo ", bien qu'ici l'origine du mot, qui signifie fibre + agglomération pour panneaux rigides et isolants, soit évidente. On pourra donc traduire par "Holzfaserplatte» ou " Holzfaserdämmplatte».

Souvent, le nom d'une marque sert à qualifier un produit, et inversement. En voici quelques exemples : pour traduire "Rigips-Platten », il faudra, selon le client ou le destinataire du texte, utiliser une traduction explicative périphrastique comme "cartons de plâtre de la marque Rigips/Knauf - marque déposée " ou plus simplement "plaques de Rigips ". Cela vaut également pour les " plaques Fermacell » en fibre de cellulose.

Les abréviations courantes en France ne sont pas faciles à traduire. Dans le domaine de la construction ou de l'industrie métallurgique, "ATEX " est un terme couramment employé pour désigner une " atmosphère explosible " dans le domaine de la protection contre les explosions (Explosionsschutz), et se traduit en allemand par "zündfähige Atmosphäre». L'abréviation existe également en Allemagne ; pour autant, personne n'en connaît la forme développée. En français, on trouve deux exemples analogues dans le domaine de la pharmacie : "mercurochrome ", qui est devenu une marque déposée et n'est plus commercialisé en France depuis 2006, et " tricostéril » qu'on traduira par «pansement de la marque Tricostéril ».

La spécificité culturelle peut évoluer au fil des temps, comme nous l'avons vu avec le "mercurochrome ". Certains éditeurs de dictionnaires décident donc de ne pas répertorier ces termes, ce qui ne nous facilite pas le travail et rend d'autant plus important le fait de se tenir constamment informé.

En conclusion, je dirais que la spécificité culturelle peut être saisie par une opposition contrastive, comme le dit le Professeur Schmitt. Il est 
déjà difficile de comparer deux cultures, mais vouloir comparer les langues et leurs structures semble être un travail d'Hercule. Il est toutefois possible de répertorier toutes ces informations, à plus forte raison en créant ses propres banques de données et en y intégrant des informations significatives. À cette fin, il convient de lire de la documentation professionnelle, de rechercher des textes semblables dans la langue cible, de voyager dans le pays, de contacter des spécialistes des deux cultures. Il faut savoir interpréter le texte en langue de départ, autrement dit savoir, le moment venu, s'il est pertinent d'indiquer la marque - Opinel par exemple - ou s'il suffit d'indiquer « couteau ". Le tout étant de saisir si la traduction s'effectue au niveau du signifiant ou du signifié.

Enfin, c'est au Professeur Daum que nous donnerons le dernier mot : "Il importe, en tant que traducteur, de connaître les plus importantes différences culturelles entre l'anglais, l'allemand, le français et le russe, pour savoir qu'en Angleterre tout est permis qui n'est pas (explicitement) défendu, alors qu'en Allemagne tout est défendu qui n'est pas permis. En France tout est permis, même ce qui est défendu et en Russie tout est défendu, même ce qui est permis.(3) "

ndm@translanguages.de

(3) «Man muss als Übersetzer die wichtigsten kulturellen Unterschiede zw. Englisch, Deutsch, Französisch und Russisch kennen, um zu wissen dass in England alles erlaubt ist, was nicht verboten ist, während in Deutschland alles verboten ist, was nicht erlaubt ist. In Frankreich ist alles erlaubt, auch wenn es verboten ist, und in Russland ist alles verboten, auch wenn es erlaubt ist ". 


\section{Bibliographie :}

Daum Ulrich (2004): «Der Turm von Babel und die Mehrsprachigkeit " Transrelations 4/2004, 8.

Schmitt Peter A. (1989d): "Kulturspezifik von Technik-Texten: Ein translatorisches Problem». Vermeer Hans J. (1989) (éd.) : Kulturspezifik des translatorischen Handelns. th - translatorisches Handeln der Abteilung allgemeine Übersetzungs- und Dolmetschwissenschaft des IÜD der Univ. Heidelberg 3, IÜD, p. 49-88.

Schmitt Peter A. (2002f): «Kultur im Fachwörterbuch?». MDÜ 4-5/2002, p. 49-57.

Schmitz Klaus-Dirk, "Einführung in die Sprachdatenverarbeitung ", Vorlesung an der Fachhochschule Köln, Sommersemester 2005.

\section{Adaptation : Michèle Le Dily, F. Plassard.}

Après une scolarité au lycée franco-allemand de Sarrebruck, des études en langues romanes (français, espagnol) et en langues slaves (russe, bulgare) à l'université de Sarrebruck puis à celle de Hambourg, Natacha Dalïgge-Momme effectue des séjours d'étude à Leningrad, Berkeley puis Paris. C'est le prélude à une carrière qui commencera dans une agence publicitaire, pour s'étoffer progressivement et venir ajouter une à une de nouvelles cordes à son arc: traductrice, interprète, chargée de cours à l'université populaire d'Abrensbourg, N. Dalïgge-Momme est expert près la Cour d'appel du Schleswig et du Tribunal d'instance de Lübeck pour le français et le russe depuis 2001. Elle préside depuis mars 2006 l'association professionnelle allemande des traducteurs et interprètes $A D \ddot{U}$ Nord. 